\title{
FÓSFORO DISPONÍVEL DETERMINADO POR LÂMINA DE RESINA ENTERRADA ${ }^{(1)}$
}

\author{
Jairo André Schlindwein ${ }^{(2)} \&$ Clesio Gianello ${ }^{(3)}$
}

\begin{abstract}
RESUMO
O uso de lâminas de resina de troca aniônica enterradas no solo permite simular, em parte, o comportamento das raízes das plantas em relação à absorção de P. Essa técnica, utilizada diretamente no solo nas mesmas condições que se cultivam as plantas, sem a necessidade de amostragem do solo, poderia ser uma metodologia promissora de determinação da disponibilidade de $P$ para as culturas. Para testar a validade da técnica, foi realizado um experimento em casa de vegetação, com cinco solos e dois teores de $P$ em que as lâminas de resina foram enterradas no solo na instalação do mesmo (dia zero) e retiradas aos $2,5,10,20$ e 40 dias depois, para avaliar a extração de $\mathrm{P}$ em diferentes solos mantidos com umidade próxima da capacidade de campo, cultivados com milho (método resina-cc), e em solos mantidos saturados com água, sem cultivo e cultivados com arroz (método resina-sat). Também retiraram-se amostras de solo para determinar o $P$ extraído pelos métodos da resina em lâminas padrão, Mehlich-1 e Mehlich-3, para correlacionar com o $\mathbf{P}$ extraído pelas culturas. O método Mehlich-1 extraiu, em média, 1,3 e 1,9 vez menos $P$ do que os métodos da resina padrão e Mehlich-3, respectivamente, e o método da resina-cc extraiu em média 2,2 vezes menos $P$ do que o método da resina-sat. Os coeficientes de determinação entre o $P$ extraído pelos métodos e o $\mathrm{P}$ absorvido pelo milho e arroz aumentaram, em média, na sequência resina-cc $<$ resina padrão $<$ Mehlich- $1<$ Mehlich-3 < resina-sat. O período de 10 dias de contato da resina com o solo foi o método que melhor estimou o $P$ extraído pelas culturas do milho e arroz. Conclui-se que o método da resina-sat pode ser utilizado eficientemente para estimar o $\mathrm{P}$ do solo disponível para as plantas.
\end{abstract}

Termos de indexação: métodos de análise de solo, difusão de $P$, solos saturados, lâmina de resina de troca aniônica.

\footnotetext{
(1) Recebido para publicação em agosto de 2007 e aprovado em dezembro de 2008 .

(2) Professor da Faculdade de Agronomia da Universidade Federal de Rondônia - UNIR. Av. Norte Sul 7300, CEP 98789000 Rolim de Moura (RO). E-mail: jairojas@unir.br

${ }^{(3)}$ Professor do Departamento de Solos, Universidade Federal do Rio Grande do Sul - UFRGS. Av. Bento Gonçalves 7712, Caixa Postal 15100, CEP 91540-000 Porto Alegre (RS). E-mail: cgianello@hotmail.com
} 


\title{
SUMMARY: SOIL PHOSPHORUS AVAILABILITY DETERMINED BY ANIONIC-EXCHANGE RESIN MEMBRANE IN THE SOIL
}

\begin{abstract}
The in situ ion exchange resin membrane allows a partial simulation of the behavior of plant roots regarding phosphorus absorption from soil solution. Soil sampling is rendered unnecessary since the technique is used directly in the soil where the plants are grown and may be a promising methodology in the determination of phosphorus availability for crops. To evaluate the technique, a greenhouse experiment was carried out with resin membranes buried in the soil when plants were sown (day zero) and removed after 2, 5, 10, 20 and 40 days, to evaluate the amount of phosphorus extracted in different soils maintained at a moisture content near the water-holding capacity, under corn (method resin-cc) and water-saturated, without cultivation and under rice (method resin-sat). Soil samples were collected to determine available $P$ by the methods resin membrane (standard), Mehlich-1 and Mehlich-3 and the extracted amount was correlated with Pabsorbed by crops. On average, Mehlich-1 extracted 1.3 and 1.9 times less phosphorus than the resin standard and Mehlich-3 methods, respectively; resin-cc method extracted, on average, 2.2 times less phosphorus than the resin-sat. The correlation coefficients among phosphorus extracted by the different methods and phosphorus absorbed by corn and rice increased in the sequence resin-cc $<$ resin standard $<$ Mehlich- $1<$ Mehlich-3 $<$ resin-sat. The correlation coefficient between phosphorus extracted with buried resin and phosphorus absorbed by corn and rice plants was highest after a period of 10 days. Results indicate that the resin-sat method is suitable to determine soil phosphorus availability to plants.
\end{abstract}

Index terms: soil analysis methods, phosphorus availability, flooded soils.

\section{INTRODUÇÃO}

A disponibilidade de $\mathrm{P}$ e outros nutrientes para as plantas normalmente está associada a uma fração na solução e à outra presente na fase sólida do solo, também denominada de fração lábil, cujos valores de $\mathrm{P}$ se relacionam com as quantidades absorvidas pelas plantas. Os fatores de solo que influenciam na disponibilidade desse nutriente para as plantas são a umidade, o teor de argila e o poder tampão de P.

$\mathrm{O}$ teor de argila influi na umidade volumétrica do solo, e ambos na difusão dos nutrientes até a superfície da raiz. Em solos argilosos, o valor do teor crítico de P para as culturas, determinado pelo método Mehlich1, é menor do que em solos arenosos (CFSRS/SC, 2004). Rein (1991) e Miola et al. (1999) observaram que a disponibilidade de P para as plantas aumentou em até 20 vezes com a umidade do solo passando de $75 \%$ da capacidade de campo para a saturação com água.

O poder tampão corresponde à variação do teor de $\mathrm{P}$ lábil em relação à alteração no seu teor solúvel (Novais \& Smyth, 1999). Kroth (1998) observou que em solos argilosos, com maiores teores de $\mathrm{P}$ disponível, portanto com maior capacidade tampão de $\mathrm{P}$, o método da resina em forma de lâminas extraiu mais $\mathrm{P}$ à medida que o tempo de extração aumentou, indicando uma possível interação positiva entre o tempo de extração e o teor de $\mathrm{P}$ do solo. Rheinheimer et al. (2003) e Gatiboni et al. (2005) observaram maior extração total de $\mathrm{P}$ pelo método da resina com mais de uma extração sucessiva.
A absorção de $\mathrm{P}$ pelas plantas só ocorre quando este está na forma iônica na solução do solo, em contato com a raiz, o que ocorre basicamente pela interceptação radicular, fluxo de massa ou por difusão. A contribuição da interceptação radicular e do fluxo de massa ao suprimento de P para as plantas, mesmo em solos com alta disponibilidade, é, em geral, menor do que $10 \%$ (Barber, 1995). O restante, mais de $90 \%$ do $\mathrm{P}$, é suprido por difusão, e, ao absorver o $\mathrm{P}$ da solução do solo em contato com a raiz, diminui o teor, formando um gradiente que propicia a difusão de um ponto de maior concentração para um de menor, em um processo dinâmico.

A resina na forma de lâmina enterrada diretamente no solo, como proposto por Schoenau \& Guerr (1996), sem a agitação de $16 \mathrm{~h}$ sugeridas no método tradicional (Amer et al., 1955; Raij et al., 1986; Tedesco et al., 1995), tem condições de extrair, ao longo do tempo, parte ou todo $\mathrm{P}$ lábil ou disponível para as plantas, semelhante ao processo de difusão de $\mathrm{P}$ até as raízes. Este método não necessita da mistura ou homogeneização do solo e não afeta significativamente as principais propriedades do solo, pois os reagentes utilizados no método apenas tamponam o meio de extração, diferentemente dos demais extratores que modificam o $\mathrm{pH}$ e provocam a dissolução e, ou, a complexação de compostos.

Se o P extraído (ou outros nutrientes) pela lâmina de resina enterrada apresentar um grau de associação com o $\mathrm{P}$ absorvido pelas plantas, então essa técnica poderia ser calibrada e utilizada para quantificar a 
disponibilidade desse nutriente para as plantas com vantagens adicionais, como dispensar a amostragem do solo, a secagem, a moagem e os procedimentos de extração, diminuindo o tempo total utilizado na quantificação da disponibilidade de nutrientes.

O objetivo deste estudo foi avaliar, em casa de vegetação, a capacidade da resina, na forma de lâmina enterrada no solo, de determinar a disponibilidade de $\mathrm{P}$ às plantas.

\section{MATERIAL E MÉTODOS}

Dois experimentos foram realizados neste estudo: um em solos com umidade próxima à de capacidade de campo, cultivados em duas épocas com milho; outro em solos mantidos sob inundação sem cultivo e outros cultivados com arroz. Em ambos os experimentos, lâminas de resina iônica na forma de membranas foram enterradas para avaliar a relação entre o $\mathrm{P}$ extraído pela resina e o $\mathrm{P}$ absorvido pelas plantas cultivadas nos mesmos solos. Também retiraram-se amostras de solo para comparação com outros métodos.

A resina aniônica na forma de lâmina utilizada neste estudo foi a do tipo AR103QDP434 da Ionics Inc. USA. As lâminas de $1 \mathrm{~mm}$ de espessura tinham $1,5 \mathrm{~cm}$ de largura e 5,0 $\mathrm{cm}$ de comprimento $\left(7,5 \mathrm{~cm}^{2}\right.$ de superfície em cada lado da lâmina).

Os experimentos foram conduzidos em vasos com cinco tipos de solos e dois teores de $\mathrm{P}$, dispostos ao acaso, na casa de vegetação junto às dependências do Departamento de Solos da Faculdade de AgronomiaUFRGS. Os solos já se encontravam em vasos e tinham diferentes características físicas, químicas e mineralógicas, e haviam sido coletados em diferentes locais do RS, adubados com diferentes doses de $\mathrm{P}$, cultivados com aveia e soja entre 1996 e 1997. Após este período, os solos permaneceram em repouso nos vasos de $40 \mathrm{dm}^{3}$ e com vegetação espontânea até 2001 quando se iniciou este trabalho. Antes dos cultivos de milho e arroz, os solos apresentavam teores muito baixos e altos de $\mathrm{P}$, determinados por Mehlich-1 (Quadro 1).

Os solos foram revolvidos antes da instalação dos experimentos, na camada de $0-15 \mathrm{~cm}$ de profundidade para homogeneização, controle de invasoras, amostragem de solo para análise e para facilitar a semeadura de milho e arroz. As lâminas de resina aniônica, previamente saturadas com $\mathrm{NaHCO}_{3}$ $0,5 \mathrm{~mol} \mathrm{~L}^{-1}$ (conforme metodologia descrita por Tedesco et al. (1995), modificada e descrita abaixo) foram enterradas de modo vertical na profundidade de 0 $5 \mathrm{~cm}$ nos dois experimentos. Para o experimento em solos com umidade próxima à capacidade de campo, com semeadura de milho em março de 2001 (primeiro cultivo) e em setembro de 2001 (segundo cultivo), o método da resina foi denominado de resina-cc. Para o experimento em solos saturados com água, sem cultivo e com semeadura de arroz no mês de janeiro de 2002, o método da resina foi denominado de resina-sat.

No experimento cultivado com milho, as lâminas de resina foram numeradas e enterradas em fileira, ao lado de sementes de milho, também numeradas (Figura 1) no mesmo dia da semeadura. A seguir, o solo foi coberto com isopor (na forma de esferas) para evitar o excesso de aquecimento do solo e a perda de água por evaporação. A superfície dos vasos foi coberta com filme plástico (perfurado para permitir a saída das plântulas de milho e para as trocas gasosas) para evitar a perda do isopor pela ação do vento. Os solos foram irrigados diariamente para a manutenção da umidade próxima à capacidade de campo. A adubação com uréia (50 kg ha-1 de $\mathrm{N}$ ) e com cloreto de $\mathrm{K}$ (50 kg ha ${ }^{-1}$ de $\mathrm{K}_{2} \mathrm{O}$, apenas no Argissolo Vermelho distrófico) foi proporcional ao volume de solo da camada de $0-20 \mathrm{~cm}$, aplicados na superfície do solo aos 10 dias após a semeadura.

\section{Quadro 1. Atributos físico e químicos de diferentes solos do RS}

\begin{tabular}{|c|c|c|c|c|}
\hline Solo (1)/u nidade & $\operatorname{Argila}^{(2)}$ & $\mathbf{p H}^{(2)}$ & $\mathbf{P}^{(2,3)}$ & $\mathbf{K}^{(2)}$ \\
\hline \multicolumn{3}{|c|}{$\mathrm{g} \mathrm{kg}^{-1}$} & \multicolumn{2}{|c|}{$-\mathrm{mg} \mathrm{dm}^{-3}$} \\
\hline PVd - B. Retiro & 100 & 5,3 & 4,4 & 35 \\
\hline PVd - B. Retiro & 100 & 5,2 & 26,6 & 30 \\
\hline LVd - Cruz Alta & 260 & 5,5 & 4,5 & 147 \\
\hline LVd - Cruz Alta & 260 & 5,8 & 27,0 & 183 \\
\hline LVd - P. Fundo & 400 & 5,7 & 4,6 & 410 \\
\hline LVd - P. Fundo & 400 & 5,3 & 40,7 & 237 \\
\hline LBa - Vacaria & 620 & 5,6 & 4,5 & 438 \\
\hline LBa - Vacaria & 620 & 5,2 & 11,9 & 369 \\
\hline LVaf - Erechim & 770 & 5,1 & 5,3 & 455 \\
\hline LVaf - Erechim & 770 & 5,6 & 24,7 & 339 \\
\hline
\end{tabular}

(1) PVd: Argissolo Vermelho distrófico, LVd: Latossolo Vermelho distrófico, LBa: Latossolo Bruno alumínico, LVaf: Latossolo Vermelho aluminoférrico. ${ }^{(2)}$ Metodologias descritas em Tedesco et al. (1995). ${ }^{(3)}$ Média de quatro avaliações antes de cada instalação das resinas no solo. 


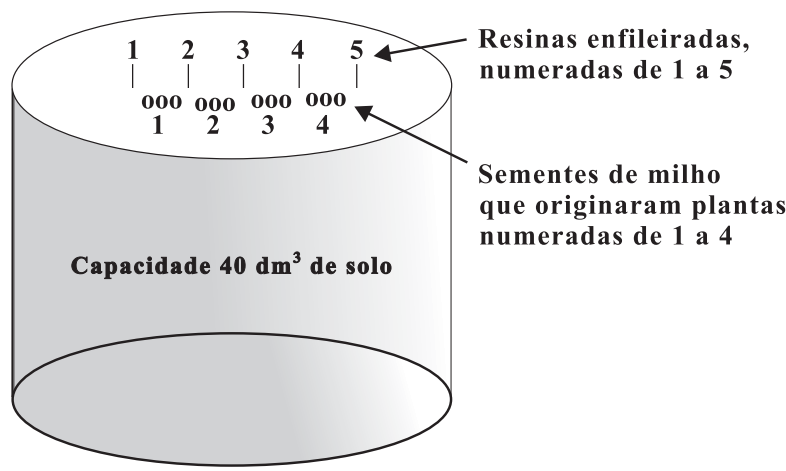

Figura 1. Disposição das resinas enterradas e das sementes de milho em vasos com capacidade de $40 \mathrm{dm}^{3}$ e raio de aproximadamente $150 \mathrm{~mm}$.

As lâminas de resina de números $2,4,1,5$ e 3 (Figura 1) foram retiradas aos 2, 5, 10,20 e 40 dias após a semeadura do milho, respectivamente. No décimo dia, foi feito o desbaste, deixando-se apenas quatro plantas enfileiradas em cada vaso. A parte aérea das plantas de milho de números 1 (mais as do desbaste), 4 e $2+3$ (Figura 1) foram retiradas para análise de tecido aos 10, 20 e 40 dias após a instalação dos experimentos, respectivamente.

No experimento com solos saturados, foram utilizados vasos de aproximadamente $1 \mathrm{dm}^{3}$ e raio de $50 \mathrm{~mm}$ para os solos sem cultivo e de aproximadamente $7 \mathrm{dm}^{3}$ e raio de $200 \mathrm{~mm}$ para os solos cultivados com arroz. Os solos utilizados para preencher estes vasos foram retirados da camada de $0-15 \mathrm{~cm}$ de profundidade dos vasos de $40 \mathrm{dm}^{3}$, cultivados anteriormente com milho. As lâminas de resina foram enterradas aleatoriamente no solo sem cultivo e no mesmo dia da semeadura do arroz. A adubação com uréia e cloreto de $\mathrm{K}$ foi igualmente feita e aplicada no arroz e no milho.

Os solos permaneceram saturados com a lâmina de água a uma altura aproximada de $2 \mathrm{~cm}$ acima da superfície do solo. Uma lâmina de resina de cada vaso foi retirada aos 2, 5, 10 e 20 dias. Retirou-se também uma lâmina, aos 40 dias após a instalação do experimento nos solos sem cultivo. A parte aérea de metade das plântulas de arroz em cada vaso foi retirada para análise de tecido aos 20 dias do plantio, e a outra metade aos 40 dias.

Os atributos de solo como o $\mathrm{pH}$, os teores de argila, o K, o P determinado pelos métodos Mehlich-1, o P extraído do solo pela resina na forma de lâmina, com agitação e o $\mathrm{P}$ absorvido pelas plantas de milho e de arroz foram determinados de acordo com Tedesco et al. (1995). As lâminas de resina no método descrito por Tedesco et al. (1995) tinham as mesmas configurações das lâminas de resina enterradas, porém $2,5 \mathrm{~cm}$ de largura por $4,0 \mathrm{~cm}$ de comprimento. O P do solo foi determinado pelo método Mehlich-3, conforme procedimentos descritos por Mehlich (1984). O P extraído do solo pelas lâminas de resina enterradas foi determinado conforme metodologia descrita por Schlindwein (2003), baseada em Tedesco et al. (1995) e descrita abaixo.

A interpretação dos resultados foi a partir de valores médios e por correlação simples entre os teores de $\mathrm{P}$ dos solos, determinados pelos diferentes métodos, ao longo do tempo, e os teores de $\mathrm{P}$ nos tecidos do milho e arroz ao longo do tempo.

\section{Procedimento para extração de fósforo por resina enterrada (resina-cc e resina-sat)}

Os materiais, as soluções, o preparo e a recuperação das resinas para novas extrações são semelhantes aos descritos por Tedesco et al. (1995).

Procedimentos com a curva-padrão: (a) colocar em frascos de $40 \mathrm{~mL}$, com tampa, as soluções da curvapadrão; (b) adicionar as resinas aniônicas previamente saturadas com $\mathrm{NaHCO}_{3} 0,5 \mathrm{~mol} \mathrm{~L}^{-1}$; (c) agitar por duas horas (110-120 oscilações por minuto); (d) lavar as resinas com jatos de água destilada; (e) colocar as resinas em frasco contendo $40 \mathrm{~mL}$ de $\mathrm{HCl}$ 0,5 mol L-1; (f) deixar em repouso durante uma hora para liberar $\mathrm{CO}_{2}$ e depois agitar por $30 \mathrm{~min}$ em agitador horizontal (110-120 oscilações por minuto) - este é o extrato de eluição; (g) pipetar $3 \mathrm{~mL}$ do extrato de eluição e colocar em copo plástico; (h) adicionar $3 \mathrm{~mL}$ de solução de molibdato de amônio; (i) adicionar três gotas da solução redutora de ácido naftol sulfônico; (j) determinar a absorbância em $660 \mathrm{~nm}$, após 30 min.

Procedimentos com as amostras: a) enterrar as lâminas de resinas aniônicas previamente saturadas com $\mathrm{NaHCO}_{3} 0,5 \mathrm{~mol} \mathrm{~L}^{-1}$; b) retirar a resina do solo, após o tempo pré-determinado, e lavar com jatos de água destilada; c) seguir os mesmos procedimentos de determinação descritos no parágrafo anterior, itens e a j.

\section{RESULTADOS E DISCUSSÃO}

Os teores de $\mathrm{P}$ extraídos pelos diferentes métodos estão apresentados no quadro 2; podem-se estimar as diferenças proporcionais de extração por eles. O método Mehlich-3 extraiu em média 1,9 vez mais $P$ do que o Mehlich-1, e a variação entre ambos foi baixa (de 1,2 a 2,3 vezes mais $\mathrm{P}$ nos solos $\mathrm{LBa}$ e $\mathrm{LVd}-\mathrm{P}$. Fundo, respectivamente). O método da resina extraiu em média 1,3 vez mais $\mathrm{P}$ do que o Mehlich-1, e a variação entre ambos foi maior (de 0,5 a 2,9 vezes mais $\mathrm{P}$ nos solos $\mathrm{PVd}$ e $\mathrm{LBa}$, respectivamente). $\mathrm{O}$ método da resina-sat extraiu em média 2,2 vezes mais $\mathrm{P}$ do que o da resina-cc, e a variação entre ambos foi grande (de 1,3 a 8,3 vezes mais $P$ nos solos $L V d-$ Cruz Alta e PVd, respectivamente).

Os métodos Mehlich-1 e Mehlich-3 são extratores ácidos que extraem quantidades de $\mathrm{P}$ mais ou menos proporcionais, como verificado em outros trabalhos realizados em solos do RS (Kroth, 1998; Schlindwein, 
Quadro 2. Fósforo extraído por diferentes métodos em solos do RS com diferentes características físicas, químicas, mineralógicas e de fertilidade

\begin{tabular}{|c|c|c|c|c|c|}
\hline \multirow{2}{*}{ Solo-unidade ${ }^{(1)}$} & \multicolumn{5}{|c|}{ Método } \\
\hline & Mehlich-1 ${ }^{(2)}$ & Mehlich-3 ${ }^{(2)}$ & $\operatorname{Resin}^{(2)}$ & $\operatorname{Resina}-c^{(3)}$ & ina-sat ${ }^{(4)}$ \\
\hline & 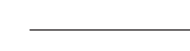 & $-\mathrm{mg} \mathrm{dm}^{-3}-$ & - & $\longrightarrow \mathrm{mg} \mathrm{cm}^{-2}$ & - \\
\hline PVd - B. Retiro & 4,4 & 6,4 & 2,2 & 0,3 & 2,5 \\
\hline PVd - B. Retiro & 26,6 & 37,5 & 14,4 & 8,6 & 15,9 \\
\hline LVd - Cruz Alta & 4,5 & 7,9 & 3,8 & 0,5 & 2,2 \\
\hline LVd - Cruz Alta & 27,0 & 45,0 & 22,7 & 5,8 & 7,3 \\
\hline LVd - P. Fundo & 4,6 & 8,2 & 4,4 & 0,5 & 2,3 \\
\hline LVd - P. Fundo & 40,7 & 94,3 & 47,6 & 6,4 & 18,7 \\
\hline LBa - Vacaria & 4,5 & 5,4 & 5,0 & 0,3 & 2,2 \\
\hline LBa - Vacaria & 11,9 & 25,1 & 35,0 & 2,3 & 5,6 \\
\hline LVaf - Erechim & 5,3 & 10,4 & 10,2 & 0,9 & 3,1 \\
\hline LVaf - Erechim & 24,7 & 50,2 & 62,5 & 7,1 & 14,3 \\
\hline Média & 15,4 & 29,0 & 20,7 & 3,3 & 7,4 \\
\hline
\end{tabular}

(1) PVd: Argissolo Vermelho distrófico, LVd: Latossolo Vermelho distrófico, LBa: Latossolo Bruno alumínico, LVaf: Latossolo Vermelho aluminoférrico. ${ }^{(2)}$ Média de quatro avaliações antes de cada instalação das resinas no solo. ${ }^{(3)}$ Resina-cc: resina enterrada no solo com umidade próxima da capacidade de campo, média de quatro épocas $(2,5,10,20$ e 40 dias) e dois cultivos de milho.

(4) Resina-sat: resina em solo saturado com água, média de quatro épocas no solo sem cultivo (2, 5, 10, 20 e 40 dias) e três épocas no solo cultivado com arroz $(2,5,10$ e 20 dias).

2003). Já o método da resina em lâminas que extrai por troca iônica extrai menos $\mathrm{P}$ em solos arenosos e mais em solos argilosos e com maiores teores, se comparado ao método Mehlich-1, como observado nos mesmos solos do RS por Kroth (1998) e Schlindwein (2003). O método Mehlich-1 extrai o P por dissolução seletiva das frações mais lábeis, a partir de diminuição do $\mathrm{pH}$. Em solos mais argilosos, com alto poder tampão, ocorre desgaste da solução extratora e o tempo de decantação de 16 h utilizado no método de extração (Tedesco et al., 1995) pode promover a readsorção de $\mathrm{P}$ já dissolvido, resultando em valores de $\mathrm{P}$ extraído menores nos solos argilosos em comparação aos solos arenosos (Kamprath \& Watson, 1980; Novais \& Smyth, 1999). Isso não ocorre com o método da resina que extrai o P da solução do solo por mecanismo de troca iônica. Neste, o P da solução passa para a resina por troca de íons originários da própria resina, que vão para a solução a fim de manter o equilíbrio químico. Com a diminuição do $\mathrm{P}$ da solução do solo, há a reposição por $\mathrm{P}$ oriundo de formas adsorvidas até a exaustão das fontes consideradas disponíveis (lábeis), que podem passar para a solução durante o período de extração devido à saturação com água e à agitação por $16 \mathrm{~h}$. Assim, a resina extrai mais $\mathrm{P}$ em solos com maior poder tampão de $\mathrm{P}$.

As resinas enterradas em solo saturado com água (resina-sat) extraíram proporcionalmente mais $\mathrm{P}$ em solos arenosos e com menores teores de $\mathrm{P}$ do que as resinas enterradas em solos com umidade próxima da de capacidade de campo (resina-cc). Em solos arenosos e com menor teor tampão de $\mathrm{P}$, a saturação do solo com água deve ter propiciado que a resina-sat extraísse todo ou quase todo o $\mathrm{P}$ disponível no período de extração, resultando na maior extração proporcional. Rheinheimer et al. (2003) observou que uma extração de $\mathrm{P}$ em relação a várias extrações pelas resinas em solo arenoso foi maior (58 \%) do que em solos argilosos (máximo $40 \%$ ).

Nos solos mais argilosos e com maior poder tampão de $\mathrm{P}$, a extração proporcional de $\mathrm{P}$ pela resina-sat foi menor em relação à dos solos arenosos, provavelmente, pelo tempo de extração não ter sido suficiente. Rheinheimer et al. (2003) observaram maior extração proporcional de $\mathrm{P}$ nos solos argilosos à medida que aumentou o número de extrações pelas resinas.

A maior extração de $\mathrm{P}$ do solo com maior umidade deve-se à maior difusão do $\mathrm{P}$ da fase sólida para a solução do solo e, deste, para a lâmina de resina de troca aniônica (Rein, 1991; Miola et al., 1999), e aos possíveis efeitos da redução do solo sob saturação (Patrick \& Mahapatra, 1968; Ponnamperoma, 1972).

Os valores mínimos, máximos e a média de matéria seca de plantas de milho e de arroz aumentaram à medida que aumentou o tempo após o plantio; já a concentração de $\mathrm{P}$ nos tecidos diminuiu à medida que aumentou o tempo de crescimento das plantas (Quadro 3). O crescimento do milho na segunda época foi maior do que na primeira, provavelmente pelo clima mais favorável no mês de setembro em relação a março. A melhor época de cultivo do milho no RS é a partir de agosto e setembro. Os valores de matéria seca e de concentração de $\mathrm{P}$ nos tecidos se correlacionaram significativamente com os teores de $\mathrm{P}$ determinado pelos diferentes métodos químicos (Quadro 4).

Os coeficientes de determinação (Quadro 4) mostram que todos os métodos apresentaram significativo grau de associação e podem ser utilizados 
Quadro 3. Valores mínimos, máximos e médios de matéria seca e teor de fósforo nos tecidos de milho e arroz aos 10, 20 e 40 dias após o plantio

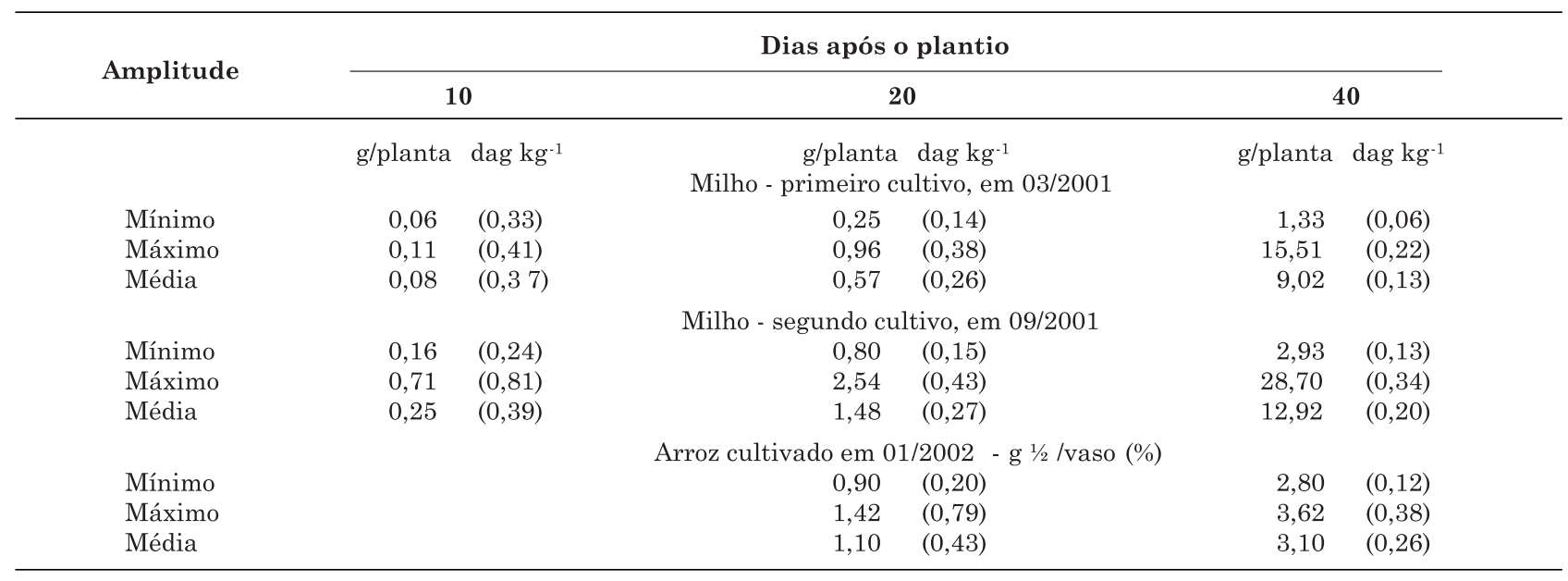

para quantificar a disponibilidade de $\mathrm{P}$ para as plantas. No entanto, em alguns casos, o grau de associação na relação pode ser considerado baixo, provavelmente pelo pequeno número de solos utilizados neste estudo associado às grandes variações físicas, químicas, mineralógicas e de fertilidade. Verificouse, porém, que em geral o método da resina-sat foi superior aos demais e pode ser uma técnica adequada para estimar a disponibilidade de $\mathrm{P}$ para solos em vasos.

A avaliação da disponibilidade de $\mathrm{P}$ em solo sem irrigação (em campo) pelo método da resina na forma de lâmina enterrada (resina-cc) pode não ser viável, pois o suprimento de $\mathrm{P}$ para as plantas ou a extração pela resina depende da umidade do solo (Rein, 1991; Miola et al., 1999; Barber, 1995). Neste trabalho, o solo foi irrigado diariamente, o que normalmente não ocorre em lavouras. Em condições de déficit hídrico, a absorção de $\mathrm{P}$ pelas plantas pode ocorrer em camadas mais profundas do perfil do solo, que geralmente apresentam maior disponibilidade de água, diferentemente das lâminas da resina que permanecem estáticas na camada de $0-5 \mathrm{~cm}$ do solo e podem extrair menos $\mathrm{P}$ devido à menor umidade.

A extração de $P$ pela resina-cc e resina-sat diferiu principalmente na primeira avaliação, aos dois dias (Figura 2). O método da resina-sat extraiu de 4 a 6 vezes mais $\mathrm{P}$ do que a resina-cc nesta avaliação. Depois deste período, nos solos mantidos com umidade próxima à de capacidade de campo, a extração de $\mathrm{P}$ pelo método da resina-cc aumentou de forma simétrica até a última avaliação.

Segundo Rein (1991) e Miola (1995), a difusão do P até uma superfície de extração é linear e mais intensa pelo menos até 24 h. Resultados de Yang et al. (1991) mostram que a extração de $\mathrm{P}$ por resinas encapsuladas e enterradas aumentou até seis dias após serem colocadas no solo, não havendo aumento significativo após este período.
Quadro 4. Coeficiente de determinação de modelo quadrático $\left(R^{2}\right)$ entre o fósforo absorvido pelas plantas cultivadas e a quantidade extraída pelos métodos, em solos do RS com diferentes características físicas, químicas, mineralógicas e de fertilidade

\begin{tabular}{lllll}
\hline Método & Milho $^{(1)}$ & Milho $^{(2)}$ & Arroz $^{(3)}$ & Média \\
\hline Mehlich-1 & $0,86^{* *}$ & $0,61^{*}$ & $0,91^{* *}$ & 0,79 \\
Mehlich- 3 & $0,84^{* *}$ & $0,68^{*}$ & $0,88^{* *}$ & 0,80 \\
Resina & $0,64^{*}$ & $0,88^{* *}$ & $0,70^{*}$ & 0,74 \\
Resina-cc(4) & $0,66^{*}$ & $0,65^{*}$ & - & 0,66 \\
Resina-sat & & & \\
Resina-sat & $0,92^{* *}$ & $-0,72^{*}$ & $0,93^{* *}$ & 0,86 \\
\hline
\end{tabular}

(1) Milho cultivado em 03/2001 (média de $\mathrm{P}$ nos tecidos aos 10, 20 e 40 dias após o plantio). ${ }^{(2)}$ Milho cultivado em 09/2000 (média de $\mathrm{P}$ nos tecidos aos 10, 20 e 40 dias após o plantio) $1 .{ }^{(3)} \mathrm{Ar}$ roz cultivado em 01/2002 (média de $\mathrm{P}$ nos tecidos aos 20 e 40 dias após o plantio). ${ }^{(4)}$ Resina-cc: resina enterrada em solo com umidade próxima à capacidade de campo (média de $\mathrm{P}$ no solo aos $2,5,10,20$ e 40 dias após a instalação das resinas). ${ }^{(5)}$ Resina-sat: resina enterrada em solo sem cultivo, saturado com água (média de $\mathrm{P}$ no solo aos 2, 5, 10, 20 e 40 dias após a instalação das resinas). ${ }^{(6)}$ Resina-sat: resina enterrada em solo saturado com água, cultivado com arroz (média de $\mathrm{P}$ no solo aos 2, 5, 10 e 20 dias após a instalação das resinas). * Significativo $(\mathrm{p}<0,05) ; * *$ Significativo $(\mathrm{p}<0,01)$.

A extração de $\mathrm{P}$ se dá pela troca de íons na superfície da lâmina de resina, a partir da difusão. No método de extração com o solo saturado com água, a umidade propiciou a difusão da maior parte do $\mathrm{P}$ extraível até os 10 dias. Depois, a difusão deve ter diminuído. Já nos solos com umidade próxima à de capacidade de campo, a menor umidade não deve ter propiciado a extração na mesma velocidade. 


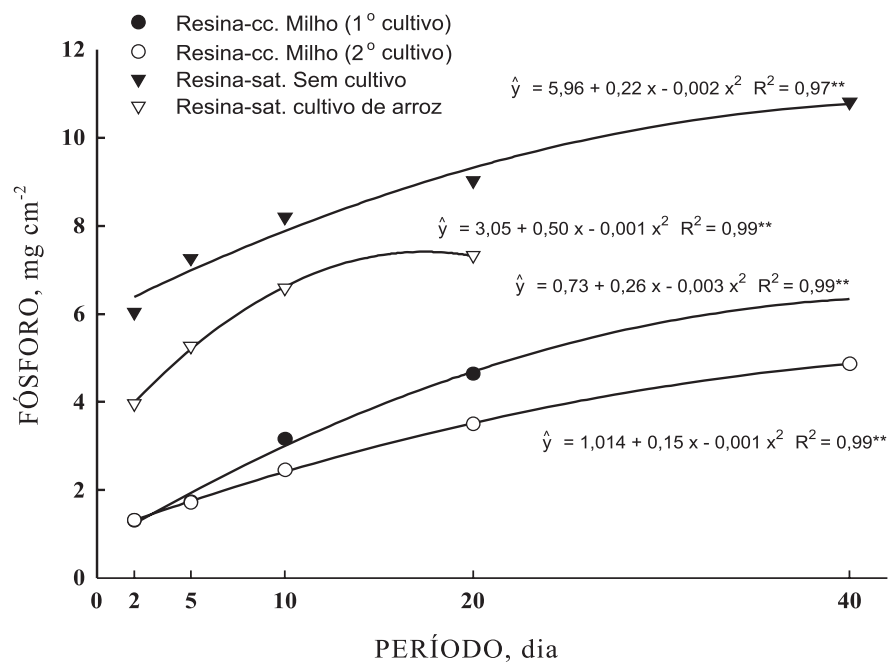

Figura 2. Relação entre o fósforo extraído pelas lâminas de resina enterradas e o período de sua permanência no solo (média de 5 solos com dois teores de fósforo), em solos do RS com diferentes características físicas, químicas, mineralógicas e de fertilidade. Resina-cc: resina em solo com umidade próxima à da capacidade de campo, resina-sat: resina em solo saturado com água. ** significativo $(p<0,01)$.

A extração de $\mathrm{P}$, pelo método da resina-cc nos solos cultivados em setembro de 2001, com milho (segundo cultivo), foi menor do que quando cultivados em março de 2001 (primeiro cultivo), especialmente aos 10 dias da instalação do experimento (Figura 2). Essa diminuição deve-se, em parte, à extração de $\mathrm{P}$ pela resina enterrada e à absorção do milho no primeiro cultivo. É possível que outros fatores, como a variação de temperatura, tenham influenciado na extração de P pela resina (Skogley et al., 1990; Kroth, 1998). A extração de $\mathrm{P}$ pelo método resina-sat cultivado com arroz foi menor do que em solo saturado com água sem cultivo (Figura 2). Isto pode ser devido à competição na extração de $\mathrm{P}$ pelas raízes das plantas, resultando na menor extração pelas lâminas de resina.

Os coeficientes de determinação (Quadro 5), que expressam a relação entre o $\mathrm{P}$ absorvido pelas plantas e o do solo, extraído pelas lâminas de resina enterradas, apresentam um grau significativo de associação na maioria dos tratamentos, principalmente para o método da resina-sat, sugerindo que este método é adequado para quantificar a disponibilidade de $\mathrm{P}$ às plantas entre 2 e 40 dias após as lâminas de resina serem enterradas. Entretanto, o coeficiente de determinação médio foi maior aos 10 dias, e deve estar relacionado ao tempo em que a extração do $\mathrm{P}$ mais se relaciona com o $\mathrm{P}$ absorvido pelas plantas. Estudos realizados por Yang et al. (1991) mostraram que seis dias foi o período necessário para avaliar a difusão de $\mathrm{P}$ que melhor se correlacionou com parâmetros de plantas.

\section{CONCLUSÕES}

1. Para solos cultivados em vasos o método da resina na forma de lâminas enterradas pode

Quadro 5. Coeficiente de determinação quadrático $\left(R^{2}\right)$ entre o fósforo absorvido pelas plantas (média de 10, 20 e 40 dias no milho e de 20 e 40 dias no arroz) e a quantidade extraída de fósforo pelas lâminas de resina enterradas, e retiradas ao longo do tempo, em solos do RS com diferentes características físicas, químicas, mineralógicas e de fertilidade

\begin{tabular}{llccccc}
\hline \multirow{2}{*}{ P extraído e P planta } & \multicolumn{5}{c}{ Tempo (dias) } & Média \\
\cline { 2 - 6 } & $\mathbf{2}$ & $\mathbf{5}$ & $\mathbf{1 0}$ & $\mathbf{2 0}$ & $\mathbf{4 0}$ \\
\hline Resina-cc e Milho $1^{\circ}$ cultivo & $0,68^{*}$ & $0,83^{* *}$ & $0,75^{* *}$ & $0,69^{*}$ & $0,64^{*}$ & 0,72 \\
Resina-cc e Milho $2^{\circ}$ cultivo & $0,26^{\text {NS }}$ & $0,44^{\text {NS }}$ & $0,60^{*}$ & $0,58^{\text {NS }}$ & $0,70^{*}$ & 0,52 \\
Resina-sat sem cultivo e arroz & $0,90^{* *}$ & $0,90^{* *}$ & $0,95^{* *}$ & $0,87^{* *}$ & $0,78^{* *}$ & 0,88 \\
Resina-sat e Arroz & $0,76^{* *}$ & $0,93^{* *}$ & $0,96^{* *}$ & $0,87^{* *}$ & - & 0,88 \\
Média & 0,65 & 0,78 & 0,82 & 0,76 & 0,71 & 0,75 \\
\hline
\end{tabular}

Resina-cc: resina em solo com umidade próximo da capacidade de campo. Resina-sat: resina em solo saturado com água. * significativo $(p<0,05)$, ** significativo $(p<0,01),{ }^{\text {ns }}$ não-significativo $(p \geq 0,05)$. 
quantificar a disponibilidade de $\mathrm{P}$ para as plantas, especialmente em solos inundados.

2. 10 dias é o período de permanência da resina enterrada, no qual a extração de $\mathrm{P}$ melhor se relaciona com a disponibilidade para as plantas.

\section{LITERATURA CITADA}

AMER, F.; BOULDING, D.R.; BLACK, C.A. \& DUKE, F.R. Characterization of soil phosphorus by anion exange resin adsorption and $\mathrm{P}^{32}$ equilibration. Plant Soil, 6:391-408, 1955.

BARBER, S.A. Soil nutrient bioavailability: A mechanistic approach. 2.ed. Toronto, John Willey, 1995. 414p.

COMISSÃO DE FERTILIDADE DO SOLO - CFSRS/SC. Manual de adubação e de calagem para os estados do Rio Grande do Sul e Santa Catarina. 10.ed. Porto Alegre, Sociedade Brasileira de Ciência do Solo - Núcleo Regional Sul/Universidade Federal do Rio Grande do Sul, 2004. 394p.

GATIBONI, L.C.; KANINSKI, J. \& RHEINHEIMER, D.S. Modificações nas formas de fósforo do solo após extrações sucessivas com Mehlich-1, Mehlich-3 e resina trocadora de ânions. R. Bras. Ci. Solo, 29:363-371, 2005.

KAMPRATH, E.J. \& WATSON, M.E. Conventional soil and tissue test for assessing the phosphorus status of soil. In: KHASAWNEH, F.E.; SAMPLE, E.C. \& KAMPRATH, E.J., eds. The role of phosphorus in agriculture. Madison, America Society of Agronomy, 1980. p.433-469.

KROTH, P.L. Disponibilidade de fósforo no solo para as plantas e fatores que afetam a extração por resina de troca em lâminas. Porto Alegre, Universidade Federal do Rio Grande do Sul, 1998. p.67. (Tese de Mestrado)

MEHLICH, A. Mehlich 3 soil test extractant: A modification of Mehlich 2 extractant. Comm. Soil Sci. Plant Anal., 15:14091416,1984

MIOLA, G.R. Extração de P, K, Ca e Mg do solo por diferentes métodos e avaliação da disponibilidade de $\mathrm{P}$ para as plantas. Porto Alegre, Universidade Federal do Rio Grande do Sul, 1995. 127p. (Tese de Mestrado)
MIOLA, G.R.; TEDESCO, M.J.; BISSANI, C.A.; GIANELLO, C. \& CAMARGO, F.A.O. Avaliação da disponibilidade de fósforo no solo para a cultura do milho. Pesq. Agropec. Bras., 34:813-819, 1999.

NOVAIS, R.F. \& SMYTH, T.J. Fósforo em solo e planta em condições tropicais. Viçosa, MG, Universidade Federal de Viçosa, 1999. 399p.

PATRICK Jr, W.H. \& MAHAPATRA, I.C. Transformation and availability to rice of nitrogen and phosphorus in waterlogged soils. Adv. Agron., 20:323-359, 1968.

PONNAMPEROMA, F.N. The chemistry of submerged soils. Adv. Agron., 24:29-96, 1972.

RAIJ, B. van; QUAGGIO, J.A. \& SILVA, N.M. Extraction os phosphorus, potassium, calcium and magnesium from soils by íon-exange resin procedure. Comm. Soil Sci. Plant Anal., 17:547-566, 1986.

REIN, T.A. Estimativa do fluxo difusivo de fósforo nos solos e avaliação de sua disponibilidade às plantas. Porto Alegre, Universidade Federal do Rio Grande do Sul, 1991. 170p. (Tese de Mestrado)

RHEINHEIMER, D.S.; ANGHINONI, I.; CONTE, E.; KANINSKI, J. \& GATIBONI, L.C. Dessorção de fósforo avaliada por extrações sucessivas em amostras de solo proveniente dos sistemas plantio direto e convencional. Ci. Rural, 33:1053-1059, 2003.

SCHLINDWEIN, J.A. Calibração de métodos de determinação de fósforo e potássiso do solo sob sistema plantio direto. Porto Alegre, Universidade Federal do Rio Grande do Sul, 2003. 169p. (Tese de Doutorado)

SCHOENAU, J. \& GUEER, K. Field mapping of soil nutrient supply rates. Better Crops Plant Food, 80:12-17, 1996.

SKOGLEY, E.O.; GEORGITIS, S.J.; YANG, E.J. \& SCHAFF, B.E. The phytoavailability soil test-PST. Comm. Soil Sci. Plant Anal., 21:1229-1243, 1990.

TEDESCO, M.J.; GIANELLO, C.; BISSANI, C.A. \& BOHNEN, S.J. Análise de solo, plantas e outros materiais. 2.ed. Porto Alegre, Universidade Federal do Rio Grande do Sul, 1995. 147p. (Boletim Técnico, 5)

YANG, J.E.; SKOGLEY, E.O. \& SCHAFF, B.E. Nutrient flux to mixed-bed ion exchange resin: temperature effects. Soil Sci. Soc. Am. J., 55:762-767, 1991. 